\title{
A síndrome de Burnout em estudantes de ciências contábeis de IES Privadas: pesquisa na cidade de São Paulo
}

\begin{abstract}
Resumo
O objetivo do estudo é identificar a prevalência e os fatores sociodemográficos, laborais e acadêmicos associados a Síndrome de Burnout em ultimoanistas de Ciências Contábeis. Burnout é o resultado do stress crônico e constitui-se em alterações nas dimensões (a) Exaustão Emocional, (b) Descrença e (c) Eficácia Profissional. É uma pesquisa empírico-analítica junto a uma amostra não probabilística de 419 alunos do período noturno de sete IES privadas da cidade de São Paulo. Como instrumentos de pesquisa foram usados o MBI-SS e um questionário para as variáveis sociodemográficas, laborais e acadêmicas. Nas três dimensões foram constatadas diferenças significativas entre os alunos, agrupados em cinco categorias de trabalho. A aferição em três dimensões indicou 46,3\% dos alunos com alteração na Exaustão Emocional, 11,2\% na Descrença e 31,3\% na Eficácia Profissional. Foram encontrados três grupos de alunos com alterações, relativas às dimensões as quais estão expostos. Estão descritos os resultados obtidos em dois grupos, expostos a duas ou mais dimensões causadoras de Burnout. O grupo 2 revelou alterações na Exaustão Emocional e em alguma outra dimensão, o grupo 3 nas três dimensões. Os alunos de uma IES revelaram nos três grupos maiores chances de exposição a Burnout. $\mathrm{O}$ mesmo ocorreu para os sujeitos do grupo 3 de outras IES. Parte dos sujeitos manifestou a sensação de que não estarem capacitados aumenta as chances de exposição a Burnout.
\end{abstract}

Palavras-chave: Síndrome de Burnout. Contabilidade. Estudantes. Carreira. Mundo do Trabalho

\begin{abstract}
Ivam Ricardo Peleias
Doutor em Ciências Contábeis pela FEAUSP-SP e Professor e pesquisador contábil na Fundação Escola de Comércio Álvares Penteado (FECAP). Contato: Avenida Liberdade, n. ${ }^{\circ}$ 532. Liberdade. São PauloSP, CEP: 01502-001

E-mail: ivamrp@fecap.br
\end{abstract}

\section{Erotides Rocha Guimarães} Mestre em Ciências Contábeis pela Fundação Escola de Comércio Álvares Penteado (FECAP) e Professor Universitário na Universidade Paulista (Unip). Contato: Rua Amazonas da Silva, n. ${ }^{\circ}$ 737. Vila Guilherme. São Paulo - SP, CEP: 02051-001 E-mail: guimaraes@targetbpo.com.br

\section{Betty Lilian Chan}

Doutora em Ciências Contábeis pela FEA-USP-SP, professora e pesquisadora contábil na Fundação Escola de Comércio Álvares Penteado (FECAP). Contato: Avenida Liberdade, n. ${ }^{\circ} 532$. Liberdade. São Paulo-SP, CEP: 01502-001 E-mail: betty.chan@fecap.br

\section{Mary Sandra Carlotto}

Doutor em Psicologia Social pela Universidade de Santiago de Compostela e Professora na Universidade do Vale do Rio dos Sinos (UNISINOS). Contato: Av. Unisinos, n. ${ }^{9}$ 950. Cristo Rei. São Leopoldo-RS, CEP: 93022-000

E-mail: mscarlotto@pesquisador.cnpq.br 


\section{Introdução}

O ingresso na graduação e no mundo do trabalho são marcos do início na profissão. Os estudantes criam expectativas profissionais, que podem vir acompanhadas de traumas e desilusão, caso não alcancem o sucesso. A inserção profissional para muitos alunos de Ciências Contábeis que atuam de dia e estudam à noite se dá pelo estágio ou emprego formal. Essa dupla jornada pode levar o trabalho a concorrer com a vida acadêmica. A depender de suas escolhas profissionais, o futuro contador encontra um campo de trabalho competitivo e globalizado, no qual lhe é exigido conhecimento técnico, domínio de idiomas, tecnologia da informação e sistemas, legislação e habilidade para atuar em equipes, bem como a aprovação no Exame de Suficiência para obter o Registro Profissional.

Entretanto, apenas a graduação não garante o êxito profissional. É preciso buscar a inserção na carreira e a educação continuada, requerida de outros contadores além dos auditores independentes, pois as empresas são exigentes com seus empregados. O futuro contador, cujos papéis acadêmico e profissional às vezes conflitam, pode manifestar sintomas de stress mental, levando à Síndrome de Burnout. Caso isso ocorra, pode haver a reprovação em disciplinas, a troca ou a desistência do curso.

Burnout é uma síndrome de exaustão emocional, despersonalização e baixa realização profissional, que pode acometer os que prestam ajuda humanitária a pessoas. Sua ocorrência para alunos em atividades pré-profissionais é estudada no Brasil e no exterior (Back, Moser \& Amorim, 2009; Borges \& Carlotto, 2004; Caballero, Abello \& Palacios, 2007; Carlotto, Câmara, Otto \& Kauffmann, 2009; Carlotto, Nakamura \& Câmara, 2006; Martinez \& Pinto, 2005; Maroco \& Tecedeiro, 2009; Shulke, Tarouco, Koetz, Ivana \& Carlotto, 2011; Tarnowski \& Carlotto, 2007; Vasconcelos, Castro, Moura Neto, Rocha, Barros \& Abdon, 2012). Há estudos nas áreas de saúde, do direito e com discentes de outras áreas.

Até o término desta pesquisa, não foram obtidos outros estudos com alunos de Ciências Contábeis no Brasil. No exterior, Law (2010) analisou alunos em cursos da área de Negócios que cursavam a disciplina contabilidade. Há estudos internacionais com contadores (Swenney \& Summers, 2002; Kalbers \& Fogarty, 2005; Larson, 2001), apontando que Burnout pode iniciar na fase estudantil em sua condição de pré-profissional.

As pesquisas em vários cursos buscaram conhecer o risco de adoecimento, para que pudessem propiciar intervenções e solucionar dificuldades futuras. A dupla jornada predominante (Nossa, 1999; Camargo \& Silva, 2006; Peleias, Petrucci, Garcia \& Silva, 2008), e a lacuna de estudos em alunos do período noturno de Ciências Contábeis na cidade de São Paulo motivaram a realização desta pesquisa, para responder à seguinte pergunta: Em que medida os ultimoanistas do período noturno de Ciências Contábeis em IES da cidade de São Paulo estão expostos à Síndrome de Burnout?

O objetivo geral é identificar a prevalência e os fatores sociodemográficos, laborais e acadêmicos associados à Síndrome de Burnout em ultimoanistas de Ciências Contábeis da Cidade de São Paulo. Outro objetivo é verificar se há diferenças significativas entre os expostos a Burnout que trabalham em firmas de auditoria externa, de contabilidade, na área contábil das empresas, estagiários e os que não trabalhavam. A hipótese é de que há diferenças significativas entre os grupos da amostra expostos a Burnout, em função de suas categorias de trabalho e das IES em que estudam.

Busca-se analisar os fatores associados a Burnout e fornecer subsídios para que os professores, Instituições de Ensino Superior (IES), recrutadores e gestores da área contábil melhorem o planejamento das atividades para esses alunos, afetando de forma positiva sua atuação na carreira contábil. 


\section{Referencial Teórico}

\subsection{Vida acadêmica, motivação e exigências profissionais para alunos de Contabilidade}

O início da graduação é um dos marcos da formação profissional em Ciências Contábeis. O ingresso na carreira contábil ao longo do curso ocorre via programas de estágio, processos seletivos em empresas, com ajuda oficial ou por ações promovidas das IES. O universo profissional dos contadores abrange as demandas das empresas e usuários dos serviços contábeis. (Pires, Ott \& Damacena, 2010)

A palavra carreira tem origem etimológica no Latim. Significa via, carraria, estrada para carros (Martins, 2010). Foi no século XIX que o termo passou a definir a trajetória profissional. Carreira é uma sequência de posições ocupadas e de trabalhos feitos durante a vida laboral, a partir da compreensão e da avaliação das vivências profissionais da pessoa ao longo da trajetória. Engloba políticas, procedimentos e decisões ligadas à vivência na empresa. (Dutra \& Veloso, 2010).

A carreira contábil requer a conclusão do curso superior e a aprovação no exame de suficiência. Alunos com ou sem o Técnico em Contabilidade buscam a graduação para crescerem na profissão. Isso pode ocorrer por influência dos pais ou parentes, oferecendo ao jovem um contato prévio antes de iniciar o curso de Ciências Contábeis.

Estudantes brasileiros de Contabilidade normalmente trabalham de dia e estudam à noite (Nossa, 1999; Camargo \& Silva, 2006; Peleias et al., 2008), o que caracteriza a dupla jornada. Muitos exercem atividade remunerada, tornando o estudo uma extensão da jornada de trabalho. Para eles, estudar é um projeto vinculado à disposição pessoal, motivada pela melhoria da renda e ascensão profissional ao fim do curso (Matsuura, 2008).

Há consequências positivas e negativas das interações entre a vida pessoal e profissional sobre a saúde física e psicológica das pessoas (Borges, Miranda \& Casado, 2010). A teoria do stress dos papéis revela que múltiplos papéis sobrecarregam as pessoas. No caso dos alunos do período noturno, a combinação de trabalho e família aumenta as responsabilidades, podendo causar impactos negativos na saúde.

A motivação dos alunos dinamiza o processo de ensino-aprendizagem, afeta a quantidade de tempo para estudo, o desempenho escolar, as realizações acadêmicas e causa satisfação imediata em suas vidas (Leal, Miranda \& Carmo, 2011). Os docentes e as IES são motivadores dos alunos e elos importantes no processo de ensino e aprendizagem, devem motivá-los, divulgando as oportunidades da profissão.

A motivação não é tema de domínio comum, em razão da profusão de termos e jargões na literatura, tais como incentivos, motivos, metas e desejos. As teorias dos conteúdos de motivação focam na pergunta "O que faz ocorrer ou parar o comportamento". As respostas concentram-se em (1) necessidades, motivos ou desejos que motivam os empregados à ação; e (2) relação dos empregados com incentivos que conduzem e os motivam ao desempenho (Megginson, Mosley \& Pietri Jr., 1986).

Leal, Carmo \& Miranda (2011) estudaram a motivação de 259 alunos a escolher Ciências Contábeis, dos quais 136 relataram experiência de trabalho na área. A comparação entre as variáveis revelou alunos preocupados em aprofundar os conhecimentos, obter uma fundamentação útil ao desempenho de sua futura atuação, obter o diploma e em comparecer às aulas para garantir frequência.

Matsuura (2008) constatou que as motivações e dificuldades de alunos noturnos de Ciências Contábeis se referem e sofrem influência do local da IES, em detrimento de outros fatores. O cansaço e a chegada à IES foram os fatores de stress desses alunos. Matsuura (2008) relatou que as mulheres oriundas do ensino médio público dependem do estágio ou trabalho, e que o cansaço da locomoção e a jornada de trabalho afetam a leitura e a interpretação de textos. Contudo, relacionar-se com colegas, docentes e coordenadores permite uma inclusão social, indicando que relacionamento e aspecto pessoal motivam a frequência ao curso.

Silva (2008) analisou egressos de IES públicas e privadas do Distrito Federal ingressantes no mundo do trabalho. Ao indagá-los sobre as razões para cursarem Ciências Contábeis, constatou que a maior motivação é ter uma formação que ofereça boas oportunidades de trabalho. Outras motivações foram influência familiar, o fato de atuarem na área e de terem o Técnico em Contabilidade. 
A atuação na área contábil requer formação superior e atualização profissional, regulada por normas do Conselho Federal de Contabilidade - CFC - para auditores e preparadores de demonstrações contábeis de determinadas empresas. Dos contadores exige-se o domínio de conceitos além dos contábeis, interação interdepartamental e conhecimento dos processos decisórios nas empresas. A sociedade e as empresas esperam que os contadores tratem, interpretem e traduzam os dados contábeis demandados pelos vários usuários.

Essas exigências motivaram estudos para avaliar a satisfação e a expectativa profissional dos futuros profissionais versus as IES e as exigências do mundo do trabalho. Sothe, Bieger, Hein e Domingues (2012) - estudaram alunos de Administração e de Ciências Contábeis de uma IES de Santa Catarina. Constataram que as desistências no curso de Ciências Contábeis, inferiores às de Administração, podem ser motivadas pelo pouco espaço para atuação na profissão.

Carvalho, Silva e Holanda (2006) - analisaram as perspectivas dos formandos de Ciências Contábeis da Universidade Estadual do Rio Grande do Norte em relação ao mercado de trabalho. Constataram que $44 \%$ dos respondentes declaram não possuir capacidade técnica suficiente para exercerem suas atividades profissionais.

Espera-se que, além do esforço do aluno, as IES o preparem para atender às demandas da profissão, tendo um conjunto de fatores que, associados, melhorem o processo de ensino e aprendizagem. A graduação deve preparar os futuros contadores para as realidades e necessidades profissionais, com o olho no futuro, no campo do entendimento de negócios e das competências pessoais (Holland, 2000).

O profissional deve se colocar no mundo do trabalho munido de diploma, competências e habilidades que atendam as demandas da sociedade e das empresas, consciente de sua responsabilidade social e de seu contínuo aprendizado (Teodoro, Teodoro, Ribeiro Filho \& Cunha, 2009). O contador deve gerir sua carreira, atento aos fatores pessoais e organizacionais, para atender aos anseios da sociedade e das empresas (Marion, 2003).

\subsection{Implicações profissionais, acadêmicas e o adoecimento}

A inserção profissional refere-se à experiência vivida, escolhas, o início de carreira e expectativas profissionais do aluno. A vida acadêmica deveria contribuir no preparo para o mundo do trabalho, mas pode ocorrer de forma inadequada, gerando ansiedade e deixando o aluno receoso em cometer erros, tais como prejudicar clientes ou não ser reconhecido por colegas e professores (Carlotto \& Câmara, 2008).

Alguns não se adaptam à realidade de estudo e de trabalho, chegando à conclusão de não terem investido adequadamente na formação, por terem uma imagem da profissão distinta da que encontraram (Dutra \& Veloso, 2010; Ferreira, 2010). Em disputas por vaga, os processos de seleção e a inserção profissional podem exercer pressões sobre os indivíduos, gerando sintomas de stress.

Os alunos de Ciências Contábeis e, em especial, os do período noturno que atuam em dupla jornada, são cobrados ao longo do curso. Deles são exigidos trabalhos em grupo, relatórios, aulas práticas, pesquisas e exames que requerem grande preparo (Caballero, Abello \& Palacios, 2007). O futuro contador pode ser alvo de vários estressores que, se persistentes, o tornam vulnerável a Síndrome de Burnout.

O adoecimento remonta à origem do homem, na busca da cura para doenças em transformação, dificultando a identificação das causas e a sua compreensão. Estudantes trabalhadores são afetados por agentes sociais, ambiente e organização do trabalho. Emergem as estruturas sociais como fatores de risco para a evolução de doenças (França \& Rodrigues, 2012). Esse desequilíbrio afeta a qualidade dos serviços prestados, o nível de produção e os lucros, na medida em que os custos e despesas aumentam com o absenteísmo, auxílio doença, reposição de empregados, transferências, novas contratações e treinamentos.

Para o estudante trabalhador que usa a capacidade física e mental como meio de retorno financeiro para a sobrevivência pessoal e familiar, a doença e a dor significam fragilidade, limitação e preocupação com a sua capacidade. Podem reduzir o desempenho, levando-o a subjugar a doença e ignorar os sinais de que algo está errado. Para as empresas, significa menor produtividade, menores resultados, necessidade de rever condições, processos de trabalho, problemas sindicais e pressão de fiscalização, além de afetar sua imagem perante a sociedade. 
Muitas vezes o modelo de compreensão de certos processos não é suficiente para entender o adoecimento. Isso ocorre nas doenças que decorrem dos esforços de adaptação às situações estressoras, apesar das evidências de que a empresa e as relações no trabalho sejam relevantes na evolução do stress. A legislação trabalhista de vários países nem sempre reconhece esses agentes estressores como produtores das doenças ocupacionais da vida moderna.

A vida moderna e as pressões do trabalho e da sociedade contribuem para o adoecimento ter outro nome: stress, uma relação particular entre a pessoa, o ambiente e as condições a que se submete. A pessoa avalia essa relação como uma ameaça ou algo que exige mais do que suas habilidades ou recursos, muitas vezes pondo em perigo seu bem estar ou sobrevivência (França \& Rodrigues, 2012).

O stress é um conjunto de reações que ocorrem em um organismo submetido a adaptação. O stress deve ser visto como uma relação particular entre uma pessoa, seu ambiente e as circunstâncias às quais se submete, avaliado como uma ameaça ou algo que exija mais do que suas próprias habilidades ou recursos e que põe em perigo seu bem estar ou sobrevivência (Seyle, H. apud França \& Rodrigues, 2012).

Fatores intrínsecos ao trabalho são marcos vitais para o estudo do stress (Cooper \& Marshall, 1978). O stress pode surgir por muito ou pouco trabalho, pressões do tempo e dos prazos, decisões para tomar, fadiga física, longas jornadas de trabalho, tendo o profissional que lidar com as mudanças no trabalho e a preocupação com os custos e despesas causados por erros cometidos (França \& Rodrigues, 2012).

O stress no trabalho ocorre na interação de características da pessoa e / ou das condições de trabalho; mas, há dúvidas sobre a importância desses fatores como causa primária (Reinhold, 2002). As diferenças individuais ajudam a predizer o que é estressante ou não para uma pessoa. Embora não se deva ignorar diferenças individuais, estudos sugerem que há certas condições de trabalho estressantes para a maioria das pessoas, que reagem de forma distinta à pressão. Alguns são mais hábeis para adaptar o seu comportamento e enfrentar o desafio (Cooper \& Marshall, 1978).

Muitos fatores alimentam as diferenças: personalidade, sexo, motivação, incapacidade de encarar problemas de determinada área, flutuações na capacidade (relativa à idade) e insight em motivações pessoais e áreas de desenvolvimento. A maioria dos estudos sobre diferenças individuais e características tem analisado as diferenças de personalidade entre alto e baixo stress de pessoas. Sob a ótica da evolução na carreira, cada etapa da vida possui seu conjunto de tensões, com diferentes evoluções de recursos de enfrentamento do stress pelo indivíduo.

O efeito do ambiente de trabalho pode causar desconforto físico e emocional se o local não estiver organizado para mitigar os fatores estressores. Os problemas com a função, sobrecarga, ambiguidade e conflito podem ser resolvidos com reestruturações, quando as funções e os trabalhos são redefinidos, identificando os profissionais desatualizados e preparando um programa de treinamento.

No caso do stress oriundo do trabalho, uma definição é como as situações em que a pessoa percebe seu ambiente de trabalho como ameaçador às suas necessidades de realização pessoal e profissional e/ ou sua saúde física ou mental. O ambiente pode prejudicar a interação com o trabalho e o local em que é realizado, pois contém demandas excessivas a ponto do profissional não conseguir enfrentar tais situações (França \& Rodrigues, 2012).

As consequências do stress são: o absenteísmo, a fuga das responsabilidades e os sintomas individuais de fadiga, agitação, entre outros, afetando a produtividade. O stress ocupacional oriundo do trabalho vem merecendo maior atenção nas últimas décadas no ambiente empresarial e na academia.

Os fatores estressores advêm do meio externo (frio, calor, condições de insalubridade), do ambiente social (o trabalho) e do mundo interno (os pensamentos e as emoções, angústia, medo, alegria e tristeza). No ensino superior, fatores acadêmicos como prazos de entrega de trabalhos e semanas de provas podem gerar o stress.

Com a pressão exercida sobre os alunos noturnos de Ciências Contábeis que atuam em dupla jornada, o processo de stress emerge em um cenário conflitante: entre a inserção profissional e a formação obtida na IES. Esse cenário com vários estressores, pode favorecer o surgimento de Burnout. 


\subsection{Implicações profissionais e a Síndrome de Burnout}

Burnout é um processo de cronificação do stress ocupacional, com consequências negativas individuais, profissionais, familiares e sociais. É um problema de saúde e qualidade de vida no trabalho, uma resposta psicofísica em função de um esforço comum, cujo resultado a pessoa considera ineficaz e insuficiente, ficando esgotado, com a sensação de desamparo, se afastando da atividade psicológica e às vezes física por causa de stress excessivo e insatisfação. Em estágios avançados, evolui para a sensação contínua de estar à beira do colapso (Bosqued, 2008).

Os estudos sobre Burnout tiveram maior divulgação com os artigos de Freundenberger (1975). Burnout significa falhar, usar a exaustão, tornar-se exausto pelo uso excessivo de energia, força ou recursos. É o que ocorre quando as pessoas se tornam inoperantes em sua atuação diária com outras pessoas. Burnout, uma síndrome de exaustão emocional, despersonalização e baixa realização profissional, não é exclusivo de equipes de instituições de autoajuda e está presente na indústria e nos negócios (Freudenberger, 1975).

A exaustão emocional é marcada pela falta ou carência de energia com um profundo esgotamento emocional e a sensação de não ser mais capaz de manter um nível psicológico. A evolução da despersonalização se manifesta pela falta de sensibilidade no atendimento, realizando-o de forma distante e impessoal (Maslach, Jackson \& Leiter, 2010).

A evolução da despersonalização resulta da exaustão emocional. Outra dimensão é a baixa realização profissional; a tendência de se autoavaliar negativamente, com a redução do sentimento de competência em relação aos ganhos pessoais obtidos no trabalho com pessoas (Maslach, Jackson \& Leiter, 2010).

Burnout não ocorre porque há algo errado com as pessoas, mas por causa de mudanças no local e na natureza do trabalho. Muitos atuam em ambientes de trabalho frios, hostis e exigentes, afetando sua rotina e vida em família (Maslach, Jackson \& Leiter, 2010). Burnout ocorre de muitas formas, que variam em sintomas e graus de pessoa para pessoa. Causa desânimo, desesperança, cinismo, isolamento, inflexibilidade, absenteísmo, entre outros fatores que afetam a produção. Os efeitos institucionais de Burnout se manifestam na queda da produção, na qualidade do trabalho, na alta rotatividade e no aumento dos acidentes ocupacionais, denegrindo a imagem da instituição e trazendo prejuízos financeiros (Pereira, Jiménez-Moreno, Kurowski, Amorim, Carlotto, Garrosa \& González,2010).

Burnout reduz o resultado das empresas, o engajamento, o comprometimento e a retenção de talentos. Pode levar à perda de talentos, pelo afastamento médico ou cessação do emprego, reduzindo a produtividade, saúde e bem-estar das pessoas, corroendo a imagem e reputação da empresa (Casserley \& Megginson, 2009).

Burnout se materializa com o tempo; muitas vezes, a pessoa não percebe os sinais de alerta e se aprofunda em um processo acumulativo de stress crônico (Reinhold, 2002). Burnout faz com que a pessoa sinta que quanto mais trabalha ou estuda, mais frustrada e exausta se torna, mais cínica em seu comportamento e menos efetiva no que quer conquistar. Isso pode acarretar desesperança e alto potencial de abandono da profissão (Freudenberger, 1975).

A perspectiva psicossocial de Burnout evolui como um processo que resulta da interação entre o ambiente de trabalho e as pessoas (Monte, 2005). Essa aproximação ajuda a entender o início, a evolução da síndrome e sintomas, em suas várias fases. Esse processo pode ser reversível se as estratégias de enfrentamento individuais forem adequadas para gerir situações de stress laboral crônico. A prolongada exposição aos sintomas de stress no início da carreira indicam que Burnout pode ocorrer na fase acadêmica e na inserção profissional do estudante no mundo do trabalho.

O debate sobre a extensão de Burnout em atividades pré-profissionais motivou estudos para avaliar a ocorrência do risco de adoecimento em alunos, que pode se estender à vida profissional e permitir intervenções para resolver possíveis problemas futuros (Martinez \& Pinto, 2005). O estudo das variáveis nos níveis de Burnout fornece informações relevantes para gerir o ensino superior (Martinez, Silva, Pinto, Soria \& Schuller, 2002). 
Burnout em alunos possui três dimensões específicas: exaustão emocional - por causa das exigências do estudo; descrença - surgimento de atitude cínica e distanciada com relação ao estudo; e ineficácia profissional - percepção de ser incompetente como estudante (Martinez e. al., 2002). O interesse por Burnout é crescente e motiva seu estudo em várias áreas, inclusive com universitários. A literatura revela não haver uma forma padrão para avaliar a ocorrência de Burnout. Algumas proposições encontradas estão a seguir sintetizadas.

Para o MBI-HSS - Maslach Burnout Inventory - Human Services Survey (Maslach, Jackson \& Leiter, 2010), Burnout pode acometer os que trabalham com pessoas. Destaca-se a exaustão emocional; como as fontes emocionais são reduzidas, as pessoas se sentem incapazes de manter um nível psicológico. Outro aspecto é a despersonalização, que traz atitudes cínicas e sentimentos sobre problemas do paciente. A percepção insensível ou desumanizada sobre os outros leva as pessoas a verem seus pacientes como merecedores de seus problemas. O MBI-HSS foi desenvolvido para avaliar, em separado, as três dimensões de Burnout.

Altos níveis de Burnout apontam índices altos nas escalas de exaustão emocional e despersonalização e baixos na realização profissional. Níveis médios apontam índices médios nas três escalas. Níveis baixos apontam índices baixos nas escalas de exaustão emocional e despersonalização e em altos na realização profissional.

Em outro instrumento, o MBI-GS (Maslach, Jackson \& Leiter, 2010), os índices altos estão acima do terço superior da distribuição, os médios no meio e os baixos abaixo do terço inferior. Maslach, Jackson e Leiter (2010) relatam o uso de escalas distintas para avaliar a ocorrência de Burnout, em função dos locais de realização dos estudos.

No Brasil não há ponto de corte definido para avaliar Burnout como em alguns países. Para os países ainda sem ponto de corte validado, Shiron (1989) sugere usar uma alternativa para identificar os níveis de Burnout com base na frequência dos sintomas. Pessoas com frequência igual ou maior a uma vez por semana desenvolveram os sintomas de Burnout. Considera-se que possuem alto nível os classificados como igual ou acima do ponto 4 da escala (uma vez por semana) para as dimensões de exaustão emocional e descrença, para a eficácia a avaliação é medida de forma invertida.

\subsection{Estudos sobre Burnout em estudantes universitários}

\subsubsection{Estudos nacionais}

O trabalho de Borges e Carlotto (2004) avaliou a ocorrência de Burnout em 255 alunos de Enfermagem, usando suas três dimensões. Mais da metade do grupo (54,9\%) frequentava aulas à noite e realizava uma atividade profissional (54,5\%). A maioria (93,7\%) não atuava na área. Apuraram um índice médio de 2,81, indicando exaustão emocional "algumas vezes ao mês". Na descrença, o índice médio foi de 1,73, indicando pouca confiança no ensino "uma vez por mês". Na eficácia profissional, o índice foi de 5,33, revelando o ensino percebido como útil na formação profissional praticamente "todos os dias".

A pesquisa conduzida por Carlotto et al. (2009) estudou uma amostra semelhante à pesquisa anterior. A Exaustão Emocional apresentou índice de 2,88, indicando desgaste emocional algumas vezes ao mês; na descrença, a média foi de 1,40 , indicando pouca confiança no ensino uma vez ao mês ou menos; Na Eficácia Profissional, a média foi de 4,90, apontando que o aluno se sente competente como estudante todos os dias.

O estudo de Tarnowski e Carlotto (2007) analisou 66 alunos de Psicologia de uma IES particular da Grande de Porto Alegre. Constataram o maior índice médio na Eficácia Profissional $(5,12 ; 5,06)$, seguida por Exaustão Emocional $(1,88 ; 2,72)$ e Descrença $(0,85 ; 1,00)$. A Eficácia profissional apresentou um índice elevado e a Descrença, baixo nos dois grupos. A Exaustão Emocional apresentou baixo índice no grupo em início de curso e próximo à média nos alunos de final de curso. 
A investigação de Carlotto e Câmara (2008) estudou as características psicométricas de 514 alunos brasileiros, de vários cursos da área da saúde de uma IES da Grande de Porto Alegre, a maioria mulheres. Obtiveram três fatores que apresentaram a mesma configuração semântica das dimensões de Burnout: exaustão emocional, eficácia profissional e descrença.

A Exaustão Emocional revelou um modelo preditor com oito variáveis, as quais explicaram 29,2\% da variância. A intenção de abandonar o curso, ter menos idade, cursar mais disciplinas, ter atividade de lazer, estar insatisfeito com o curso, estar em semestre avançado, fazer curso complementar e ter experiência profissional na área predizem a exaustão emocional.

$\mathrm{Na}$ Descrença, as variáveis explicativas foram: intenção de abandonar ou permanecer no curso, atividade de lazer, satisfação com o curso e idade, explicando $20,1 \%$ da dimensão em estudo. As variáveis pensar em abandonar o curso, não ter atividade de lazer, estar insatisfeito com o curso e ser mais jovem influenciam o sentimento de descrença em relação aos estudos.

A Eficácia Profissional foi explicada pelas variáveis: abandono do curso, atividade de lazer, experiência profissional na área e satisfação com o curso, perfazendo $11,4 \%$ da variância da dimensão. A intenção de permanecer no curso, ter atividade de lazer, ter experiência profissional na área e estar satisfeito com o curso explicam o sentimento de eficácia profissional nos estudos.

O trabalho de Back, Moser e Amorim (2009) avaliou 76 alunos do $2^{\circ}$ período noturno de Direito de uma IES de Curitiba-PR (57\% mulheres). Constataram que 18,42\% dos sujeitos (63,6\% mulheres), obtiveram pontuações para serem diagnosticados com Burnout. Obtiveram altos escores na Despersonalização e Exaustão Emocional e baixos escores em Realização Pessoal.

Outra pesquisa de Carlotto et al. (2009) analisou 239 alunos de Psicologia de uma IES da Grande Porto Alegre (87,4\% de mulheres), totalmente dedicadas ao curso (52,6\%). A Exaustão Emocional revelou índice médio de 2,50, indicando desgaste emocional "algumas vezes ao mês". Na Descrença, o índice médio foi de 1,20, indicando não acreditarem no ensino somente "uma vez por mês". Na Eficácia Profissional, o índice foi de 5,14, indicando que o aluno se sente competente como estudante praticamente "todos os dias".

O estudo de Schulke et al. (2011) analisou 101 estagiários de Fisioterapia de uma IES (84,8\% mulheres), que estuda e trabalha (53,5\%). Apuraram índice de Exaustão Emocional de 3,38, em uma escala de 1 a 5. Na Descrença, o baixo índice de 1,64 indicou confiança no curso e na aprendizagem recebida. Na Eficácia Profissional, apuraram o alto índice de 4,85, indicando que os alunos se sentem competentes como estudante praticamente "todos os dias".

A investigação de Vasconcelos et al. (2012) analisou 50 alunos do último ano de Fisioterapia (76\% de mulheres). Na Exaustão Emocional, apuraram 54\% com escore elevado e 2\% baixo. Na Despersonalização, $40 \%$ com escore baixo e $36 \%$ médio. Na realização profissional, apuraram $46 \%$ com escore baixo e $44 \%$ médio.

\subsubsection{Estudos internacionais}

O trabalho de Martinez et al. (2002) usou uma escala de 0 a 1 para analisar 1.350 alunos, 46,1\% espanhóis e 53,9\% portugueses ( $74 \%$ mulheres). Na Exaustão Emocional, apuraram a $=0,79$, para o cinismo, a=0,81, e para a despersonalização, $a=0,73$. Os espanhóis reportaram valores maiores em cinismo, exaustão emocional e mais baixos em despersonalização. Houve diferenças significativas nos três fatores, com maiores níveis de exaustão emocional e cinismo nos espanhóis; nos portugueses a despersonalização teve valores mais elevados.

A pesquisa de Sweeney e Summers (2002) avaliou o impacto de Burnout e o efeito da sobrecarga de trabalho em contadores de uma firma de auditoria americana, com 13 escritórios em sete estados, durante os períodos de fechamento, em dois momentos; o $1^{\circ}$, em novembro de um ano, com o envio de 426 questionários e 284 (67\%) respondidos, formando o time 1; o 2º em março do ano seguinte, com o envio de 381 questionários e 209 respondidos (55\%), formando o time 2. Constataram maiores níveis de exposição para o time 2, avaliado após o fechamento. Não foi medido o nível de desgaste após o fechamento com a equipe voltando a uma vida normal, ficando obscuro o tempo de permanência desses níveis elevados. 
O estudo de Martinez e Pinto (2005) analisou Burnout e sua relação com variáveis acadêmicas junto a 1.988 alunos ( $31,2 \%$ espanhóis e $68,8 \%$ portugueses), dos quais $77 \%$ mulheres. Constataram, usando uma escala de 0 a 1 , valor $\mathrm{a}=0,79$ na exaustão, a $=0,81$ para o cinismo e a $=0,74$ para a eficácia acadêmica, os quais superaram a referência aceitável de 0,70 (Nunnaly \& Bernstein, 1994).

A investigação de Kalbers e Fogarty (2005) analisou 298 auditores internos, em cooperação com 23 organizações representativas de indústrias dos Estados Unidos, com apoio do The Institute of Internal Auditors (IAA). Desse total, 59\% eram mulheres, com um tempo médio de prática de de 7,1 anos, e quase $30 \%$ com mais de 10 anos de experiência. Três hipoteses foram testadas.

A $1^{\text {a }}$ hipótese foi confirmada. O lócus de controle interno teve influência negativa significativa nas três dimensões de Burnout. Os auditores internos com menores sintomas tenderam ao lócus de controle interno. A $2^{a}$ sugeriu uma relação negativa entre as competências percebidas e as dimensões de Burnout e foi confirmada para a baixa realização profissional. Não houve relação entre capacidades pessoais e exaustão emocional e nem entre a percepção de competências pessoais e despersonalização. A $2^{a}$ não foi confirmada para duas dimensões. $\mathrm{Na} 3^{\mathrm{a}}$, confirmou-se a relação negativa entre credibilidade organizacional e Burnout; porém, não ocorreu associação direta entre a confiança organizacional e a realização pessoal reduzida nos auditores internos.

O trabalho de Caballero, Abello e Palacios, (2007) analisou 202 estudantes noturnos colombianos de psicologia (77,2\% mulheres). Constataram Burnout acadêmico em 41,6\% dos alunos (distribuídos entre nível médio e alto), sugerindo que experimentaram a sensação de não dar mais de si mesmo, e cinismo, sobre o valor e o significado do trabalho, enquanto $38,2 \%$ apresentam exaustão, $29,7 \%$ cinismo e $48,6 \%$ sentem-se ineficazes.

A pesquisa de Maroco e Tecedeiro (2009) analisou 654 alunos portugueses de Psicologia. Constataram que a versão original do MBI-SS permite calcular os escores de Exaustão, Descrença e Eficácia. Uma pessoa é diagnosticada com Burnout em relação ao seu grupo se estiver acima do percentil 66 dos scores de Exaustão e Descrença e abaixo do percentil 33 dos scores de Realização. Os valores decílicos e os percentis 66 e 33 dos 3 fatores da MBI-SS foram descritos em uma tabela elaborada pelos autores.

O estudo de Law (2010) analisou uma amostra de 196 alunos de Negócios de três classes de uma universidade estatal americana. Constataram, nas dimensões exaustão emocional, despersonalização e baixa realização profissional, alphas 0,88, 0,78 e 0,74, próximos aos de Maslach; Jackson e Leiter,(2010), estes de $0,90,0,79$, e 0,71 .

A investigação de Larson (2001) avaliou as diferenças da suscetibilidade entre 677 auditores internos, nos fatores de tensão de trabalho causadores de Burnout, com dados fornecidos pelo American Institute of Certified Public Accountants (AICPA). Os respondentes tinham idade média de 34 anos, tempo médio de prática de oito anos e $64 \%$ eram homens. As mulheres relataram desgaste ligeiramente maior do que os homens $(3,08)$ e $(2,93)$, com as solteiras apresentando índice superior ao das casadas $(3,22)$ e $(2,99)$. Não ocorreu o mesmo com os homens solteiros em relação aos casados, $(2,92)$ e $(2,93)$, e o maior índice relatado pelas mulheres foi entre as solteiras sem filhos $(3,22)$, e nos homens, entre os solteiros com filhos $(3,81)$.

\section{Metodologia}

A pesquisa é empírico-analítica e de caráter quantitativo. Foram selecionados, no sistema E-MEC, doze cursos de Ciências Contábeis presenciais na cidade de São Paulo, oferecidos no período noturno, com notas de 2 a 5 no ENADE. Foram remetidos e-mails e feitos contatos telefônicos com os coordenadores. Feita a aproximação e expostos os objetivos da pesquisa, obteve-se a autorização junto a sete cursos. Os cursos para os quais a pesquisa foi autorizada são oferecidos pelas Instituições de Ensino Superior (IES) privadas descritas na Tabela 01. Por questões éticas e de sigilo, optou-se por não divulgar os nomes das IES. 
Tabela 01

IES que Autorizaram a Aplicação do Questionário

\begin{tabular}{|c|c|c|}
\hline IES - Campus & Conceito & Frequência \\
\hline A - Centro & 5 & 87 \\
\hline B - Centro & 5 & 51 \\
\hline C - Centro & 4 & 71 \\
\hline D - Zona Oeste & 4 & 39 \\
\hline E - Zona Oeste & 4 & 53 \\
\hline F - Centro & 3 & 21 \\
\hline G - Zona Oeste & 3 & 97 \\
\hline Total de questionários obtidos & & 419 \\
\hline
\end{tabular}

Por conta dos poucos estudos no Brasil, decidiu-se usar o questionário de Carlotto e Câmara (2006) com 15 questões, traduzido e adaptado da versão em inglês de Schaufeli, Martínez, Pinto, Salanova e Bakker (2002). Este questionário foi usado por duas razões: 1) tem como origem um questionário validado e; 2) está adaptado e testado na realidade brasileira.

Adotou-se a sugestão de Shiron (1989), para identificar Burnout em função da frequência da manifestação dos sintomas. Usou-se, na identificação da frequência, a escala de evolução dos sintomas igual ou superior a uma vez por semana, sugerida por Shiron (1989). Avaliou-se a presença das três dimensões pela contagem das frequências de respostas, usando uma escala de pontuação, semelhante à de Likert, sendo (0) para nunca, (1) uma vez ao ano, (2) uma vez ao mês ou menos, (3) algumas vezes ao mês, (4) uma vez por semana, (5) algumas vezes por semana e (6) todos os dias.

Os ultimoanistas, todos atuando em dupla jornada, foram escolhidos por serem sujeitos com escolhas profissionais sedimentadas e por terem experiência profissional maior, em relação a alunos de períodos anteriores. Os questionários foram aplicados de forma presencial, com a autorização das IES e coordenadores dos sete cursos objeto da pesquisa. Os achados e sua consequente análise estão limitados à amostra analisada.

A presente pesquisa adotou como definição operacional de possíveis expostos ao risco de Burnout os seguintes critérios para cada dimensão:

- Exaustão Emocional (EE) (5 questões): média das respostas acima do ponto de corte 4;

- Descrença (DE) (4 questões): média das respostas acima do ponto de corte 4;

- Eficácia Profissional (EP) (4 questões): média das respostas abaixo do ponto de corte 4;

Com o intuito de identificar as variáveis que melhor ajudam na distinção entre alunos que (a) não são classificados como possíveis expostos ao risco de Burnout e (b) daqueles que são expostos, aplicou-se o modelo de regressão logística binária, fazendo-se uso do método stepwise para seleção das variáveis significativas. O nível de significância adotado foi de $5 \%$.

O modelo de regressão logística binária é usado quando a variável dependente (resposta) é dicotômica, ou seja, apresenta apenas dois valores possíveis representando sucesso ou falha ou, mais geralmente, a presença ou ausência de um atributo de interesse (McCullagh \& Nelder, 1989; Hosmer \& Lemeshow, 2000). Este tipo de modelo pertence a uma classe de modelos introduzida por Nelder \& Wedderburn (1972), com o nome de Modelos Lineares Generalizados (MLG ou GLM, no inglês), que são uma extensão dos modelos lineares clássicos. Desta maneira, a variável resposta, que antes precisava ser normal, poderia ser qualquer uma pertencente a um grupo específico de distribuições, chamado de família exponencial de distribuições. 
Foram desenvolvidos 2 modelos de regressão logística, alterando-se a definição da variável resposta (variável dependente $=1$ ), conforme os critérios apresentados a seguir:

- Grupo 2: aqueles considerados expostos ao risco de Burnout em termos de Exaustão Emocional e em outra dimensão;

- Grupo 3: aqueles considerados expostos ao risco de Burnout nas três dimensões estudadas.

Nos resultados, são discutidas as variáveis significativas em cada modelo. Para o desenvolvimento dos testes estatísticos, foi usado o software R, disponível para download em www.r-project.org.

\section{Apresentação e Discussão dos Resultados}

De 424 questionários aplicados, cinco foram descartados em função de erros, ausências no preenchimento e de respostas incoerentes. A amostra foi composta de 419 questionários. Algumas variáveis categóricas não foram respondidas, por esta razão o total de algumas respostas é inferior ao da amostra.

\subsection{Perfil dos Respondentes}

A síntese do perfil da amostra é descrita a seguir, na Tabela 02 .

\section{Tabela 02}

\section{Frequência dos Motivos da Escolha da IES}

\begin{tabular}{llcc}
\hline & \multicolumn{1}{c}{ Escolha da IES } & Frequência & Percentual \\
\hline & \multicolumn{1}{c}{ Razão } & 123 & 29,4 \\
\hline 1 & Por ser mais próximo a minha residência & 109 & 26,1 \\
\hline 2 & Pela sua pontuação no MEC & 101 & 24,2 \\
\hline 3 & Pelo "nome” da instituição & 35 & 8,4 \\
\hline 4 & Outro & 34 & 8,1 \\
\hline 5 & Por ser mais próximo ao meu trabalho & 10 & 2,4 \\
\hline 6 & Pelo Guia do Estudante & 5 & 1,1 \\
\hline 7 & Pelo valor da mensalidade & 1 & 0,3 \\
\hline 8 & Não tinha o curso que eu queria na IES ou campus que desejava & 418 & 100,0 \\
\hline Total & & 5 & \\
\hline
\end{tabular}

A nota do ENADE (2) e o conceito atribuído à IES (3) somam 50,3\% das escolhas e foram apontados como fatores que interferem na escolha da IES (Pires, Ott \& Damacena, 2010). Destacou-se a distância (itens 1 e 5), responsável por 37,8\% na escolha da IES. Matsuura (2008) apontou a distância como uma dificuldade para o aluno. Estas variáveis responderam por $88,1 \%$ das razões de escolha da IES.

A maioria (79,0\%) não possui união estável e $58,2 \%$ é do sexo feminino. Resultados semelhantes sobre o gênero foram obtidos por Leal, Miranda e Carmo, (2011), Borges e Carlotto (2004), Schulke et al. (2011), Vasconcelos et al. (2012) e Tarnowski e Carlotto (2007), e quanto ao estado civil por Larson (2011).

$\mathrm{Na}$ divisão do tempo entre as vidas acadêmica e profissional, $81,4 \%$ declarou trabalhar 8 horas por dia, caracterizando a dupla jornada, o que para Bosqued (2008) pode ocasionar o início do stress crônico. Quanto ao estágio, 9,6\% atuavam dessa maneira. A variável "somente estuda" foi escolhida por 6,92\% e $2,15 \%$ declararam não trabalhar. Considerado o fato de os sujeitos serem ultimoanistas de Ciências Contábeis e de mais de 90,0\% exercer atividade remunerada é um indicativo da alta empregabilidade na profissão contábil. 
Dos que não trabalhavam, $64,7 \%$ eram mantidos pelas famílias, os demais recebiam bolsas ou incentivos do governo. Esta condição não lhes retira as atribuições e exigências da vida acadêmica. Caballero, Abello e Palacios, (2007) apontam o stress no ambiente acadêmico como fator para o início do processo de adoecimento.

Da amostra final, 81,6\% declarou-se capacitado profissionalmente. Quanto aos 18,4\% que se consideraram inaptos, se considerado o fato de serem ultimoanistas prestes a obterem o diploma, os números são consideráveis.

Para $84,9 \%$ essa é a primeira graduação; 15,1\% declarou possuir outro curso. A baixa porcentagem para a segunda graduação pode ser explicada pelas idades média (25,1 anos) e mínima da amostra (21 anos), que sugere pequeno lapso de tempo entre a conclusão do ensino médio e o ingresso no curso superior.

\subsection{Estatísticas sobre as alterações e variáveis de resposta}

Esta etapa buscou medir os níveis de exposição dos alunos, assim como Shiron (1989). Aqui foi usada uma variável dummy, Considerando que " 0 " indica possíveis não expostos e "1" os possíveis expostos. Consideradas as três dimensões, 194 respondentes (46,3\%) relataram alterações na Exaustão Emocional, 47 (11,2\%) alteração na Descrença e 131 (31,4\%) alteração na Eficácia Profissional, conforme mostra a Tabela 03.

Tabela 03

Frequência de Alterações nas Dimensões de Burnout

\begin{tabular}{ccccccc}
\hline \multirow{2}{*}{ Alteração } & \multicolumn{2}{c}{ Exaustão emocional } & \multicolumn{2}{c}{ Descrença } & \multicolumn{2}{c}{ Eficácia profissional } \\
\cline { 2 - 7 } & Frequência & $\%$ & Frequência & $\%$ & Frequência & $\%$ \\
\hline 0 & 225 & 53,7 & 372 & 88,8 & 288 & 68,7 \\
\hline 1 & 194 & 46,3 & 47 & 11,2 & 131 & 31,4 \\
\hline Total & 419 & 100,0 & 419 & 100,0 & 419 & 100,0 \\
\hline
\end{tabular}

Com base nestas respostas, foram criados três grupos de respondentes, para medir o grau de exposição à patologia (Reinhold ,2002), conforme a Tabela 04.

Tabela 04

Frequência das Alterações por Grupo

\begin{tabular}{ccccccc}
\hline \multirow{2}{*}{ Alteração } & \multicolumn{2}{c}{ Grupo 1 } & \multicolumn{2}{c}{ Grupo 2 } & \multicolumn{2}{c}{ Grupo 3 } \\
\cline { 2 - 7 } & Frequência & $\%$ & Frequência & $\%$ & Frequência & $\%$ \\
\hline 0 & 140 & 33,4 & 352 & 84,0 & 402 & 95,0 \\
\hline 1 & 279 & 66,6 & 67 & 16,0 & 17 & 4,0 \\
\hline Total & 419 & 100,0 & 419 & 100,0 & 419 & 100,0 \\
\hline
\end{tabular}

O grupo 1 agregou 279 alunos (66,6\% da amostra) que relataram alteração em uma das 3 dimensões, o grupo 2, 67 alunos (16,0\%) alterações na Exaustão Emocional e em outra dimensão, o grupo 3, 17 alunos $(4,0 \%)$ com alterações nas três dimensões.

Foram analisados os resultados estatisticamente significativos para os grupos 2 e 3 , com o uso da regressão logística. Burnout resulta da conjugação de vários fatores. Uma pessoa pode manifestar sintomas de uma dimensão e superá-los de forma mais rápida do que quando manifesta sintomas de duas ou mais dimensões. As frequências e percentagens para os grupos 2 e 3 foram calculadas para expostos e não expostos. Nas análises para os expostos, considerou-se as percentagens em relação ao total das respostas para os dois grupos. A última coluna das tabelas a seguir inclui os totais e percentuais da somatória entre expostos e não expostos. 


\subsubsection{Descrição dos resultados significativos para o grupo 2}

O grupo 2 agregou alunos com alterações na Exaustão Emocional e em outra dimensão, com variabilidade entre Descrença e Eficácia Profissional. A Tabela 05 revela que 16,7\% dos que trabalham confirmaram os achados de Dutra \& Veloso (2010), quanto aos problemas de adaptar-se ao fato de trabalhar e estudar. As pressões e cobranças acadêmicas apontadas por Caballero, Abello e Palacios, (2007) aparecem nos 10,5\% que não trabalham e manifestaram sinais de exposição.

Tabela 05

Expostos e não Expostos por Ocupação Atual Grupo 2

\begin{tabular}{cccc}
\hline Ocupação atual & Não Exposto & Exposto & Total \\
\hline Trabalho/estágio & $315(83,3 \%)$ & $63(16,7 \%)$ & $378(90,9 \%)$ \\
\hline Não trabalha & $34(89,5 \%)$ & $4(10,5 \%)$ & $38(9,1 \%)$ \\
\hline Total & $349(83,9 \%)$ & $67(16,1 \%)$ & $416(100,0 \%)$ \\
\hline
\end{tabular}

A Tabela 06 apresenta os alunos que trabalham separados por categorias e a origem dos recursos dos que não o fazem. Destes, 52,8\% dos expostos atuavam na área contábil (16,0\% em empresas de contabilidade, $14,3 \%$ na área contábil das empresas e $22,5 \%$ em empresas de auditoria externa). Hernandes (2011) atribui o stress do profissional contábil à complexidade das atividades realizadas, ao grande fluxo de informação, aos prazos e às obrigações inerentes às suas funções. $O$ autor assevera que a profissão será uma das mais estressantes no futuro, comprometendo a qualidade de vida e a saúde do trabalhador. Não se constatou exposição dentre os bolsistas que não trabalhavam à época; entretanto, $14,8 \%$ dos mantidos pelas famílias relatou exposição.

Tabela 06

Expostos e não Expostos por Categoria de Trabalho Grupo 2

\begin{tabular}{llccc}
\hline & \multicolumn{1}{c}{ Categoria } & Não Exposto & Exposto & Total \\
\hline & Trabalha em empresa de contabilidade & $89(84,0 \%)$ & $17(16,0 \%)$ & $106(25,5 \%)$ \\
\cline { 2 - 5 } & Outras categorias de empresa, na área contábil & $72(86,0 \%)$ & $12(14,3 \%)$ & $84(20,2 \%)$ \\
\cline { 2 - 5 } Estágio/Trabalho & É empresário do ramo de contabilidade & $2(100,0 \%)$ & $0(0,0 \%)$ & $2(0,5 \%)$ \\
\cline { 2 - 5 } & Trabalha em empresa de auditoria externa & $38(77,5 \%)$ & $11(22,5 \%)$ & $49(11,8 \%)$ \\
\cline { 2 - 5 } & Outras categorias de empresa, em outras áreas & $91(84,3 \%)$ & $17(15,7 \%)$ & $108(26,0 \%)$ \\
\cline { 2 - 5 } & Outros & $23(79,3 \%)$ & $6(20,7 \%)$ & $29(7,0 \%)$ \\
\hline \multirow{3}{*}{ Não trabalha/só estuda } & Outros & $2(100,0 \%)$ & $0(0,0 \%)$ & $2(0,5 \%)$ \\
\cline { 2 - 5 } & A família banca os estudos & $23(85,2 \%)$ & $4(14,8 \%)$ & $27(6,5 \%)$ \\
\cline { 2 - 5 } & Detentor de bolsas & $9(100,0 \%)$ & $0(0,0 \%)$ & $9(2,2 \%)$ \\
\hline Total & & $349(83,9 \%)$ & $67(16,1 \%)$ & $416(100,0 \%)$ \\
\hline
\end{tabular}

As competências e habilidades profissionais precisam ser formadas durante a vida acadêmica (Pires, Ott \& Damacena, 2010). Esta responsabilidade pode causar pressões por parte das IES e agravar o nível de exposição dos alunos. Em alguns casos, pode ocorrer a desistência do curso, como apontado por Sothe et al. (2012). 
A Tabela 07 aponta o percentual de expostos e não expostos do grupo 2, por IES. Os alunos da IES C relataram maiores percentuais de exposição, 26,8\%. Em seguida, observa-se as IES E (19,2\%), F (19,1\%), D (18,4\%), B (15,7\%), A (14,9\%) e G (6,5\%).

A cobrança por eficiência, produtividade e a competitividade no âmbito acadêmico podem gerar insegurança, angústia e baixa autoestima. A soma destes elementos pode, em muitos casos, explicar as altas taxas de exposição a Burnout encontradas nas universidades.

Tabela 07

Expostos e não Expostos por IES Grupo 2

\begin{tabular}{cccc}
\hline Instituição & Não Exposto & Exposto & Total \\
\hline A & $74(85,1)$ & $13(15,0 \%)$ & $87(20,9 \%)$ \\
\hline G & $90(93,8 \%)$ & $6(6,3 \%)$ & $96(23,1 \%)$ \\
\hline B & $43(84,3 \%)$ & $8(15,7 \%)$ & $51(12,3 \%)$ \\
\hline C & $52(73,2 \%)$ & $19(26,8 \%)$ & $71(17,1 \%)$ \\
\hline E & $42(80,8 \%)$ & $10(19,2 \%)$ & $52(12,5 \%)$ \\
\hline F & $17(810,0 \%)$ & $4(19,1 \%)$ & $21(5,1 \%)$ \\
\hline D & $31(81,6 \%)$ & $7(18,4 \%)$ & $38(9,1 \%)$ \\
\hline Total & $349(83,9 \%)$ & $67(16,1 \%)$ & $416(100,0 \%)$ \\
\hline
\end{tabular}

A sensação de incapacidade profissional requer atenção (Borges \& Carlotto, 2004). Por essa razão, $45,3 \%$ dos pesquisados merecem cautela por relatarem exposição a Burnout. As percentagens de expostos descritas na Tabela 08 indicam que esta parte da amostra pode apresentar problemas de exaustão emocional e de eficácia profissional, razão pela qual podem requerer cuidados especiais.

Tabela 08

Expostos e não Expostos por Capacitação Profissional Grupo 2

\begin{tabular}{cccc}
\hline Capacitação Profissional & Não Exposto & Exposto & Total \\
\hline Não & $51(67,1 \%)$ & $25(32,9 \%)$ & $76(18,3 \%)$ \\
\hline Sim & $298(87,7 \%)$ & $42(12,4 \%)$ & $340(81,7 \%)$ \\
\hline Total & $349(83,9 \%)$ & $67(16,1 \%)$ & $416(100,0 \%)$ \\
\hline
\end{tabular}

A seguir são apresentados os resultados sintetizados do modelo de regressão logística, aplicando-se o método de seleção de variáveis stepwise a um nível de significância de 5\%.

Tabela 09

Resultado do Modelo de Regressão Logística

\begin{tabular}{lllll}
\multicolumn{1}{c}{ Parâmetro } & Categoria & Estimativa & Erro Padrão & p-valor \\
\hline Intercepto & & $-1,0559$ & 0,1729 & $<, 0001^{*}$ \\
\hline Instituição categoria & C & 0,4594 & 0,1607 & 0,0043 \\
\hline Capacitação Profissional & Não & 0,6559 & 0,1503 & $<, 0001$ \\
\hline
\end{tabular}

*Variáveis significativas a 5\% de significância. 
Nesse modelo, foram significativas apenas as variáveis relativas a instituição de ensino e capacitação profissional. A seguir são apresentados os valores de Odds Ratio para cada variável.

Tabela 10

Odds Ratio

\begin{tabular}{|c|c|c|c|}
\hline \multirow{2}{*}{ Variáveis } & \multicolumn{2}{|c|}{ Burnout } & \multirow{2}{*}{ Odds Ratio } \\
\hline & Não Expostos & Expostos & \\
\hline \multicolumn{4}{|c|}{ Instituição categoria } \\
\hline $\mathrm{C}$ & $52(73,24 \%)$ & $19(26,76 \%)$ & $2,506(1,135 ; 4,706)^{\star}$ \\
\hline Outros & $297(86,09 \%)$ & $48(13,91 \%)$ & 1 \\
\hline \multicolumn{4}{|c|}{ Capacitação Profissional } \\
\hline Não & $51(67,11 \%)$ & $25(32,89 \%)$ & $3,713(2,060 ; 6,694)^{*}$ \\
\hline Sim & 298 (87,65\%) & $42(12,35 \%)$ & 1 \\
\hline
\end{tabular}

*Variáveis significativas a 5\% de significância.

Das informações da tabela acima, nota-se que:

- Para a variável Instituição: ser estudante da IES C aumenta em 2,506 vezes a chance de estar exposto a Burnout do que estudar nas outras IES incluídas na pesquisa;

- Para a variável Capacitação Profissional: não se sentir capacitado para o exercício da profissão aumenta em 3,713 vezes a chance de estar exposto a Burnout do que se sentir capacitado.

Além disso, aplicou-se o teste de Hosmer e Lemeshow (1980), o qual indicou que o modelo ajustado é adequado (não rejeitou a hipótese nula, tendo sido encontrados p-valor de 0,7674 e 0,9015, respectivamente).

\subsubsection{Descrição dos resultados significativos para o grupo 3}

O grupo 3 agregou alunos que relataram alterações nas três dimensões. A Tabela 11 indica que 4,0\% dos que trabalham apresentaram sinais de exposição, os quais podem estar associados a fatores internos do ambiente laboral (Cooper \& Marshall, 1978). O grupo que não trabalha relatou maior percentual de exposição, cerca de 5,3\%.

Tabela 11

Expostos e não expostos por ocupação atual grupo 3

\begin{tabular}{cccc}
\hline Ocupação atual & Não Exposto & Exposto & Total \\
\hline Trabalho/estágio & $363(96,0 \%)$ & $15(4,0 \%)$ & $378(90,9 \%)$ \\
\hline Não trabalha & $36(94,7 \%)$ & $2(5,3 \%)$ & $38(9,1 \%)$ \\
\hline Total & $399(95,9 \%)$ & $17(4,1 \%)$ & $416(100,0 \%)$ \\
\hline
\end{tabular}

Os que declararam trabalhar foram agrupados em categorias, o que visou medir o nível de exposição por setor de atuação. A Tabela 12 indica que os que atuam em empresas de auditoria externa possuem maior nível de exposição, 6,1\%. Alberton e Beuren (2003) dizem que os altos índices de stress em auditores externos podem ser explicados pelas várias competências e habilidades exigidas para o cargo. 
Alberton e Beuren (2002) ressaltam que os auditores passam por avaliações periódicas, que medem conhecimentos contábeis, tributários, societários, auditoria e fluência na língua inglesa, outros atributos como flexibilidade, lealdade, ética profissional, relação com a política corporativa da empresa, aparência, comportamento, motivação e gestão de pessoas. Esses requisitos ajudam a compreender as repetidas taxas de stress entre os auditores externos, nos três grupos desta pesquisa.

Alunos que atuam em empresas de contabilidade (5,7\%) possivelmente estão expostos. Dos que atuam na área contábil de outras empresas, 2,4\% apontam sinais de exposição. Os empresários contábeis não manifestaram sintomas de exposição. Para os que não trabalhavam cujas famílias pagam os estudos, a exposição foi de 7,4\%. Assim como no grupo 2, nenhum bolsista apresentou exposição a Burnout. Estes achados estão na Tabela 12.

Leal, Miranda e Carmo (2011) e Matsuura (2008) constataram que alunos de Ciências Contábeis que trabalhavam ligados à área contábil podem estar expostos a alto nível de stress. Os disputados processos de seleção, os altos requisitos de recrutamento e as exigências das empresas, inerentes à responsabilidade que compete ao profissional contábil ajudam a explicar os altos níveis de stress (Villela \& Nascimento, 2003).

\section{Tabela 12}

\section{Expostos e não expostos por categoria de trabalho grupo 3}

\begin{tabular}{llccc}
\hline & \multicolumn{1}{c}{ Categoria } & Não Exposto & Exposto & \multicolumn{1}{c}{ Total } \\
\hline & Trabalha em empresa de contabilidade & $100(94,3 \%)$ & $6(5,7 \%)$ & $106(25,5 \%)$ \\
\cline { 2 - 5 } & $\begin{array}{l}\text { Outras categorias de empresa, na área } \\
\text { contábil }\end{array}$ & $82(97,6)$ & $2(2,4 \%)$ & $84(20,2 \%)$ \\
\cline { 2 - 5 } Estágio/Trabalho & É empresário do ramo de contabilidade & $2(100,0 \%)$ & $0(0,0 \%)$ & $2(0,5 \%)$ \\
\cline { 2 - 5 } & Trabalha em empresa de auditoria externa & $46(93,9 \%)$ & $3(6,1 \%)$ & $49(11,8 \%)$ \\
\cline { 2 - 5 } & $\begin{array}{l}\text { Outras categorias de empresa, em outras } \\
\text { áreas }\end{array}$ & $106(98,2 \%)$ & $2(1,9 \%)$ & $108(20,0 \%)$ \\
\cline { 2 - 5 } & Outros & $27(93,1 \%)$ & $2(6,9 \%)$ & $29(7,0 \%)$ \\
\hline \multirow{3}{*}{ Não trabalha/ só estuda } & Outros & $2(100,0 \%)$ & $0(0,0 \%)$ & $2(0,5 \%)$ \\
\cline { 2 - 5 } & A família banca os estudos & $25(92,6 \%)$ & $2(7,4 \%)$ & $27(6,5 \%)$ \\
\cline { 2 - 5 } & Detentor de bolsas & $9(100,0 \%)$ & $0(0,0 \%)$ & $9(2,2 \%)$ \\
\hline Total & & $399(95,9 \%)$ & $17(4,1 \%)$ & $416(100,0 \%)$ \\
\hline
\end{tabular}

Nem todos conseguem lidar com o alto nível muitas vezes exigido (Marion, 2003). A Tabela 13 indica que os alunos da IES C continuam com os maiores índices de exposição, de 8,4\%. Constatou-se 7,9\% de exposição na IES D, 4,8 na F, 3,1\% na G, 2,3\% na A, 2,0\% na B e $1,9 \%$ na E.

O resultado cíclico encontrado nos grupos 2 e 3 , em que os alunos da IES C relataram maiores índices de exposição a Burnout continua sendo explicado pelas exigências da IES. Ao buscarem formar contadores qualificados e que atendam às demandas do mundo do trabalho, algumas IES podem exigir maiores esforços e dedicação. Esta possível exigência pode causar o constatado por Carvalho, Silva e Holanda, (2006), em que 44,0\% dos formados e atuantes na área contábil relataram não possuir capacidade técnica suficiente para exercerem suas atividades.

Quanto à responsabilidade das IES, Teodoro et al. (2009), Holland (2000) e Marion (2003) alertam que não basta contribuir para inserir o profissional no mundo do trabalho, munido do diploma de graduação. São necessárias competências e habilidades que subsidiem as demandas das organizações. Além destas responsabilidades, espera-se que as IES promovam maior desenvolvimento das habilidades e competências, elevando as exigências e cobranças a seus estudantes. 
Tabela 13

Expostos e não expostos por IES grupo 3

\begin{tabular}{cccc}
\hline Instituição & Não Exposto & Exposto & Total \\
\hline A & $85(97,7 \%)$ & $2(2,3 \%)$ & $87(20,9 \%)$ \\
\hline G & $93(96,9 \%)$ & $3(3,1 \%)$ & $96(23,1 \%)$ \\
\hline B & $50(98,0 \%)$ & $1(2,0 \%)$ & $51(12,3 \%)$ \\
\hline C & $65(91,6 \%)$ & $6(8,5 \%)$ & $71(17,1 \%)$ \\
\hline E & $51(98,1 \%)$ & $1(1,9 \%)$ & $52(12,5 \%)$ \\
\hline F & $20(95,2 \%)$ & $1(4,8 \%)$ & $21(5,1 \%)$ \\
\hline D & $35(92,1 \%)$ & $3(7,9 \%)$ & $38(9,1 \%)$ \\
\hline Total & $399(95,9 \%)$ & $17(4,1 \%)$ & $416(100,0 \%)$ \\
\hline
\end{tabular}

Maslach, Jackson e Leiter (2010) sugerem que a baixa realização profissional pode explicar as alterações na Eficácia Profissional. A Tabela 14 aponta para 11,8\% dos que não se sentem capacitados profissionalmente e manifestaram sinais de exposição, além dos $2,4 \%$ que se sentem aptos para o exercício da função. Esses estudantes relataram alterações nas três dimensões, e por isso merecem mais atenção.

Tabela 14

Expostos e não expostos por capacitação profissional grupo 3

\begin{tabular}{cccc}
\hline Capacitação Profissional & Não Exposto & Exposto & Total \\
\hline Não & $67(88,2 \%)$ & $9(11,8 \%)$ & $76(18,3 \%)$ \\
\hline Sim & $332(97,6 \%)(97,65 \%)$ & $8(2,4 \%)$ & $340(81,7 \%)$ \\
\hline Total & $399(95,9 \%)$ & $17(4,1 \%)$ & $416(100,0 \%)$ \\
\hline
\end{tabular}

A Tabela 15 sintetiza os resultados do modelo de regressão logística, usando o método de seleção de variáveis stepwise a um nível de significância de 5\%.

Tabela 15

Resultado Do Modelo De Regressão Logística

\begin{tabular}{ccccc}
\hline Parâmetro & Categoria & Estimativa & Erro Padrão & p-valor \\
\hline Intercepto & & $-2,7138$ & 0,2555 & $<, 0001^{*}$ \\
\hline Instituição categoria & C / D & 0,6319 & 0,2561 & $0,0136^{*}$ \\
\hline Capacitação Profissional & Não & 0,8790 & 0,2561 & $0,0006^{*}$ \\
\hline
\end{tabular}

*Variáveis significativas a 5\% de significância. 
Tabela 16

Odds Ratio

\begin{tabular}{|c|c|c|c|}
\hline \multirow{2}{*}{ Variáveis } & \multicolumn{2}{|c|}{ Burnout } & \multirow{2}{*}{ Odds Ratio } \\
\hline & Não Expostos & Expostos & \\
\hline \multicolumn{4}{|c|}{ Instituição categoria } \\
\hline$C / D$ & $100(91,74 \%)$ & $9(8,26 \%)$ & $3,539(1,297 ; 9,657)^{\star}$ \\
\hline Outros & $299(97,39 \%)$ & $8(2,61 \%)$ & 1 \\
\hline \multicolumn{4}{|c|}{ Capacitação Profissional } \\
\hline Não & $67(88,16 \%)$ & $9(11,84 \%)$ & $5,801(2,126 ; 15,832)^{*}$ \\
\hline Sim & $332(97,65 \%)$ & $8(2,35 \%)$ & 1 \\
\hline
\end{tabular}

*Variáveis significativas a 5\% de significância.

Das informações da tabela acima, nota-se que:

- Para a variável Instituição: ser estudante das IES C e D aumenta em 3,539 vezes a chance de estar exposto a Burnout do que estudar nas outras IES incluídas na pesquisa;

- Para a variável Capacitação Profissional: não se sentir capacitado para o exercício da profissão aumenta em 5,801 vezes a chance de estar exposto a Burnout do que se sentir capacitado.

Além disso, ressalta-se que no teste de Hosmer e Lemeshow (1980), os resultados sugerem que o modelo ajustado é adequado (não rejeitou a hipótese nula, p-valor de 0,7812 e 0,6551, respectivamente).

\section{Conclusões}

Burnout resulta de stress crônico, que leva a alteração nas dimensões Exaustão Emocional, Descrença e Eficácia Profissional. Para identificar se a prevalência e os fatores laborais, sociodemográficos e acadêmicos contribuíam significativamente para a exposição a Burnout em ultimoanistas de Ciências Contábeis de sete IES da cidade de São Paulo, realizou-se a pesquisa com 419 estudantes. Destes, 46,3\% relataram alteração na Exaustão Emocional, 11,2\% alteração na Descrença e 31,3\% alteração na Eficácia Profissional.

Nos dois grupos analisados, as variáveis mais significativas para distinguir entre os possíveis expostos e não expostos ao risco de Burnout foram IES e capacitação profissional. Os achados da pesquisa permitiram responder à questão formulada e confirmar a hipótese de que há diferenças significativas entre os grupos da amostra expostos a Burnout, em função de suas categorias de trabalho e das IES em que estudam.

A sociedade e as organizações exigem mais que um apurador de dados. Elaborar relatórios contábeis e financeiros é tarefa comezinha, o futuro contador precisa traduzir, interpretar informações e adequá-las com a eficiência e rapidez requerida aos processos decisórios. Este cenário pode ocasionar o stress laboral, evoluindo para Burnout. 
Os alunos das IES C e D relataram maiores chances de exposição nos dois grupos. A necessidade de manter ou aumentar a nota do ENADE e de zelar pelo nome da IES faz com que a IES eleve as exigências aos alunos. Parte dos alunos considerou-se profissionalmente incapaz. Dentre os que se consideram capacitados foram constatadas falhas na Eficácia Profissional.

Os achados sugerem a necessidade de ações preventivas que possam mitigar os sintomas identificados. A busca pelo bem-estar, a saúde física e mental, as melhorias nas condições de trabalho, a qualidade de vida, entre outras atitudes, são ações essenciais para reduzir a quantidade de trabalhadores que adoecem gradativa e silenciosamente.

Os resultados obtidos estão adstritos à amostra estudada. Recomenda-se que outros interessados explorem o tema em outras IES da mesma região ou de outras localidades, com o intuito de aprofundar e analisar, de forma comparativa e complementar, os resultados obtidos. A continuidade nas pesquisas contribuirá para a identificação precoce, a prevenção e, quando for o caso, a indicação dos tratamentos para a Síndrome de Burnout.

\section{Referências}

Alberton, L., \& Beuren, I. M. (2002). A formação comportamental de auditores contábeis independentes: um estudo multicaso - Revista Eletrônica de Ciências Administrativas, 1(2), pp. 1-15.

Back, C. M., Moser, A. M., \& Amorim, C. (2009) Burnout e autoestima em estudantes de direito, IX Congresso Nacional de Educação e o Encontro Sul Brasileiro de Psicopedagogia. Curitiba, Paraná, Brasil, 3.

Borges, A. M. B., \& Carlotto, M.S. (2004). Síndrome de Burnout e fatores de estresse em estudantes de um curso técnico de enfermagem. Aletheia, 19, pp. 45-56. Recuperado em 20 de junho, 2016, de http://pepsic.bvsalud.org/scielo.php?script=sci_arttext\&pid=S1413-03942004000100005\&lng=p t\&tlng=pt.

Borges, F. J., Miranda, B. S., \& Casado, T. (2010) Desenvolvimento da carreira: Trabalho, família e outras dimensões do projeto de vida da pessoa. In: J.S. Dutra (Org.), Gestão de carreiras na empresa contemporânea, pp. 172-189. São Paulo: Atlas.

Bosqued, M. (2008). Quemados el síndrome de Burnout: Que és y como superarlo. Barcelona: Paidós.

Caballero C. C., Abello, R, \& Palacios S. J. (2007). Relación del burnout y el rendimiento académico con la satisfacción frente a los estudios en estudiantes universitarios. Avances en Psicología Latinoamericana, 25(2), pp. 98-111.

Camargo, R. G., \& Silva, S. M. M. (2006). Aprendizagem de adultos e pensamento crítico nos cursos de Ciências Contábeis. In: Peleias, I. R. (Org). Didática do ensino da contabilidade - aplicável a outros cursos superiores. São Paulo, Saraiva.

Carlotto, M. S., Nakamura, A. P., \& Câmara, S. G. (2006). Síndrome de Burnout em estudantes universitários da área da saúde. Psico, 37(1), pp. 57-62.

Carlotto, M. S., \& Câmara, S. G. (2006). Características psicométricas do Maslach Burnout Inventory Student Survey (MBI_SS) em estudantes universitários brasileiros. PSICO-USF. 11(2), pp. 167-173.

Carlotto, M. S. \& Câmara, S. G. (2008). Preditores da Síndrome de Burnout em estudantes universitários. Pensamiento Psicológico, Cali-4(10), pp. 101-109.

Carlotto, M. S., Câmara, S. G., Otto, F. \& Kauffmann, P. (2009). Síndrome de Burnout e coping em estudantes de Psicologia. Boletim de Psicologia, 59(131), pp. 167-178. 
Carvalho, J. R. M., Silva, M., \& Holanda, F. M. A. (2006). Perspectivas dos formandos do curso de ciências contábeis em relação ao mercado de trabalho de uma IES pública no estado do Rio Grande do Norte. Encontro Nacional De Pós-Graduação Em Administração. Salvador, Bahia, Brasil. 30. Recuperado em 10 novembro, 2016 de http://www.anpad.org.br/enanpad/2006/dwn/enanpad2006-epqb-1220.pdf

Casserley,T., \& Megginson, D. (2009). Learning from Burnout. Oxford: Elsevier.

Cooper, C. L., \& Marshall, J. (1978). Sources of managerial and collar e stress. New York: Wiley.

Dutra, J. S., \& Veloso, E. F. R. (2010). Evolução do conceito de carreira e sua aplicação para a organização e para as pessoas. In: J. S. Dutra (Org.), Gestão de carreiras na empresa contemporânea, 1, pp. 3-39. São Paulo: Atlas.

Ferreira, M. A. A. (2010). Orientação profissional. In: J. S. Dutra (Org.). Gestão de carreiras na empresa contemporânea, pp. 155-171, São Paulo: Atlas.

França, A. C. L. \& Rodrigues, A. V. (2012). Stress e trabalho uma abordagem psicossomática, (4ª ed.). São Paulo: Atlas.

Freudenberger, H. J. (1975). The staff burn-out syndrome in alternative institutions, psychotherapy: theory, research and practice, 12(1), pp. 73-82. doi:10.1037/h0086411

Hernandes, A. (2011). O estresse e o profissional da contabilidade. Marketing contábil. Recuperado em 10 novembro, $2016 \mathrm{de} \mathrm{http://www.andersonhernandes.com.br/2011/07/02/o-estresse-e-o-profis-}$ sional-contabi//

Holland, C. B. (2000). A profissão de contador na atualidade, e sugestões para o seu futuro. Revista da Associação de Executivos de Finanças, Administração e Contabilidade. Recuperado em 10 novembro, 2016 de www.aicpa.org/edu/corecomp.htm

Hosmer, D. W. \& Lemeshow, S (1980). Goodness-of-fit tests for the multiple logistics regression model. Communications in statistics: Theory and methods, New York., 9(10), pp. 1043-1069.

Kalbers, L. P.\& Forgaty, T. J. (2005). Antecedents to Internal Auditor BURNOUT. Journal of Managerial Issues; 1(17) pp. 101.

Larson, L. L. (2001). Gender differences in internal auditor job Burnout. Internal Auditing; 26(1) pp.11.

Law, D. W. (2010). A Measure of Burnout for Business Students. Journal of Education for Business 85, pp.195-202. doi:10.1080/08832320903218133

Leal, E. A., Miranda, G. J. \& Carmo, C. R. S. (2011). Teoria da autodeterminação: uma análise da motivação dos estudantes do Curso de Ciências Contábeis. Revista Contabilidade \& Finanças - USP, 24(62), pp.162-173.

Marion, J. C. (2003). Preparando-se para a Profissão do Futuro. Recuperado em 10 novembro, 2016 de http://www.classecontabil.com.br/artigos/ver/134

Maroco, J. \& Tecedeiro, M. (2009). Inventário de Burnout de maslach para estudantes portugueses. Psicologia, Saúde e Doenças. 10(2), pp. 227-236.

Martins, H.T. (2010). Gestão de Carreiras na era do conhecimento: Abordagem conceitual e resultados de pesquisas. Rio de Janeiro: Qualitymark.

Martínez, I. M. M., Silva, A.L., Pinto, A.M., Soria, M.S. \& Schuller, S. (2002). Burnout en estudiantes universitarios de España y Portugal un estúdio transcultural. Ansiedad y estrés, 8, pp. 13-23.

Martínez, I. M. M., \& Pinto, A. M. (2005). Burnout en estudiantes universitários de España y Portugal y su relación com variables académicas. Aletheia, 21, pp. 21-30. 
Maslach, C.; Jackson, S. E. \& Leiter, M. P. (2010). MBI maslach Burnout inventory, manual. (3a ed.) Palo Alto, CA.

Matsuura, A. A. (2008). Motivações e dificuldades de estudantes do curso de ciências contábeis no período noturno da cidade de São Paulo. Fundação Escola de Comércio Álvares Penteado - FECAP, São Paulo, SP, Brasil.

Mccullagh, P. Nelder, J. A. (1989). Generalized Linear Models. 2nd ed. London: Chapman and Hall/CRC.

Megginson, L. C., Mosley, D. C., \& Pietri P. H. Jr., (1986). Administração conceitos e aplicações. São Paulo: Harper \& Row do Brasil.

Monte, P. R. G. (2005). El síndrome de quemarse por el trabajo Burnout. Madrid: Ediciones Pirámide.

Nelder, J. A., \& Wedderburn, R. W. N. (1972). Generalized linear models. Journal of the Royal Statistical Society, [S.I], 135(3), pp. 370-384. doi:10.2307/2344614

Nossa, V. (1999). A necessidade de profesores qualificados e atualizados para o ensino da Contabilidade. Revista de Contabilidade do CRC-SP. São Paulo: Conselho Regional de Contabilidade, 9.

Nunnaly, Jc C., \& Bernstein, I. H. (1994). Psychometric Teory. 3 ed. New York: McGraw-Hill.

Peleias, I. R., Petrucci, V. B. C., Garcia, M. N., \& Silva, D. (2008). Pesquisa sobre a percepção dos alunos do $1^{\circ}$. Ano de Ciências Contábeis na cidade de São Paulo em relação às dificuldades por eles percebidas no período noturno. Revista Universo Contábil, 4(1), pp. 81-94.

Pereira, A.M.T.B. Jiménez-Moreno, B., Kurowski, C.M., Amorim, C.A., Cartollo, R.S., Garrosa, E.S. \& González, J.L. (2010). Burnout: Quando o trabalho ameaça o bem estar do trabalhador. (4º ed.) São Paulo: Casa do Psicólogo.

Pires, C. B., Ott, E., \& Damacena, C. (2010). A formação do Contador e a demanda do mercado de trabalho na Região Metropolitana de Porto Alegre (RS). BASE - Revista de Administração e Contabilidade da UNISINOS, 7(4), pp. 315-327. doi:10.4013/base.2010.74.05

Reinhold, H. H. (2002). O Burnout. In: M. Lipp, (Org.), Stress do professor. (pp. 63-80). Campinas: Papirus.

Schaufeli, W. B., Marínez, I. M., Pinto, A. M., Salanova, M. \& Bakker, A. B. (2002). Burnout and engagement in university students. A Cross National Study, 33 (5), pp.464-481.

Shiron, A. (1989). Burnout in work organizations. In Cooper, C.L. Robertson, I. International Review of Industrial and Organizational Psychology. New York: Wiley \& Sons, pp. 25-48.

Shulke, A.P., Tarouco, A.M., Koetz, A., Ivana, A \& Carlotto, M.S. (2011). A Síndrome de BURNOUT em Estagiários de Fisioterapia. Revista Diversitas - Perspectivas en Psicologia, 7(1), pp. 167-177.

Silva, R. M. P. (2008). Percepção de formandos em ciências contábeis sobre sua preparação para o ingresso no mercado de trabalho: um estudo no âmbito do Distrito Federal. Dissertação de mestrado, Universidade de Brasília, Brasília, Distrito Federal, Brasil.

Sothe, A., Bieger, E.I., Hein, N.S., Domingues, M.J.C.S. (2012). Satisfação e perspectiva profissionais dos acadêmicos dos cursos de Administração e de Ciências Contábeis de uma Instituição de ensino de Santa Catarina. RBC-Revista Brasileira de Contabilidade, 196, pp. 53-65.

Sweeney, J. T. \& Summers, S. L. (2002). The effect of the busy season workload on public accountants' job Burnout. Behavioral Research in Accounting. Sarasota. (14) pp. 223-245. doi:10.2308/ bria.2002.14.1.223

Tarnowski, M., \& Carlotto, M. S. (2007). Síndrome de Burnout em estudantes de Psicologia, Temas em Psicologia, Porto Alegre, Rio Grande do Sul, Brasil. 15(2) pp. 173-180. 
Teodoro, A. F. O, Teodoro, J.C., Ribeiro Filho, J.F. \& Cunha, S.A. (2009). Empregabilidade e (in)formação: Um estudo sobre os fatores que impactam as atividades dos contadores no município de Recife Pernambuco, Congresso Virtual Brasileiro de Administração, 6. Recuperado em 10 novembro, 2016 de http://www.convibra.com.br/2009/artigos/138_0

Vasconcelos, R. P., Castro, C.A., Moura Neto, A.R., Rocha, S.G., Barros, A.R.C. \& Abdon, A.P.V. (2012) A ocorrência da síndrome de Burnout nos acadêmicos do último ano do curso de fisioterapia. Revista Fisioter S fun, Fortaleza. Ceará, Brasil, 1(1), pp. 42-46.

Villela, L. E., \& Nascimento, L. M. F. (2003). Competências pós-industriais exigidas pelas empresas a estagiários e recém formados, Encontro Nacional Da Associação Nacional de Programas de Pós-Graduação em Administração (ANPAD), Atibaia. Recuperado em 10 novembro, 2016 de www.anpad. org.br/diversos/trabalhos/EnANPAD/enanpad_2003/GRT/2003_GRT1662.pdf 